\title{
Autism spectrum disorder and celiac disease: no evidence for a link
}

\author{
Transtorno autístico e doença celíaca: sem evidências de associação \\ Icaro Camargo Batista', Lenora Gandolfi, Yanna Karla Medeiros Nobrega ${ }^{3}$, Rodrigo Coutinho Almeida4, \\ Lucas Malta Almeida5, Dioclécio Campos Junior', Riccardo Pratesi
}

\begin{abstract}
Objective: To evaluate the possible association between celiac disease (CD) and/or gluten sensitivity (GS) and autism spectrum disorder (ASD). Methods: Occurrences of CD were determined in a group of children and adolescents affected by ASD and, conversely, occurrences of ASD were assessed in a group of biopsy-proven celiac patients. To detect the possible existence of GS, the levels of antigliadin antibodies in ASD patients were assessed and compared with the levels in a group of non-celiac children. Results: The prevalence of CD or GS in ASD patients was not greater than in groups originating from the same geographical area. Similarly the prevalence of ASD was not greater than in a group of biopsy-proven CD patients. Conclusion: No statistically demonstrable association was found between CD or GS and ASD. Consequently, routine screening for CD or GS in all patients with ASD is, at this moment, neither justified nor cost-effective.
\end{abstract}

Key words: autistic spectrum disorder, celiac disease, prevalence, mass screening.

\section{RESUMO}

Objetivo: Avaliar a possível associação entre doença celíaca (DC) e/ou sensibilidade ao glúten (SG) e transtorno do espectro autista (TEA). Métodos: Ocorrências de DC foram determinadas em um grupo de crianças e adolescentes afetados pelo TEA e a ocorrência d TEA foi avaliada em um grupo de pacientes com DC comprovada por biópsia. Para detectar a possivel existência de SG, foram determinados níveis de anticorpos antigliadina em pacientes com TEA e comparados ao grupo de crianças sem a doença celíaca. Resultados: A prevalência de DC ou SG não foi maior no grupo de pacientes com TEA quando comparada a grupos de indivíduos originários da mesma região geográfica. De modo similar, a prevalência do TEA não foi maior ao ser comparada ao grupo de pacientes com DC. Conclusão: Não houve associação estatisticamente demonstrável entre DC ou SG e TEA. Consequentemente, não são justificáveis, no momento, exames de rotina para detecção de DC ou SG em pacientes com TEA.

Palavras-Chave: transtorno autístico, doença celíaca, prevalência, programa de rastreamento.

Autism is a disorder of neural development characterized by impaired social interaction and communication, and by restricted and repetitive behavior. It is one of the three recognized autism spectrum disorders (ASDs); the other two are Asperger's syndrome, which lacks delays in cognitive development and language, and pervasive developmental disorder - not otherwise specified (commonly abbreviated as PDD-NOS), which is diagnosed when the full set of criteria for autism or Asperger's syndrome is not met ${ }^{1}$. Children with ASD frequently display tendencies toward self-harm, irritability, hyperactivity, erratic and aggressive behavior. One of the most confounding aspects of ASDs is their wide phenotypic heterogeneity, which suggests that ASDs may possibly encompass several different and specific disorders with different etiologies sharing a common behavioral clinical picture. Although the cause of ASDs and their associated symptoms remain unclear, it is likely that their complex etiology arises from the combined effects of multiple susceptibility alleles in concert with environmental or other non-genetic factors. Evidence from twin and family studies clearly

\footnotetext{
${ }^{1}$ Graduate Program in Health Sciences, School of Health Sciences, University of Brasília, Brasília DF, Brazil;

${ }^{2}$ Graduate Program in Health Sciences; Department of Pediatrics; Celiac Disease Research Center, School of Medicine, University of Brasilia, Brasília DF, Brazil.

${ }^{3}$ Celiac Disease Research Center; Department of Pharmaceutical Sciences, School of Health Sciences, University of Brasília, Brasília DF, Brazil. ${ }^{4}$ Graduate Program in Health Sciences, School of Health Sciences; Celiac Disease Research Center, School of Medicine, University of Brasília, Brasília DF, Brazil.

${ }^{5}$ Celiac Disease Research Center, School of Medicine, University of Brasília, Brasília DF, Brazil.

Correspondence: Riccardo Pratesi; SQN 212/Bloco F/Apt.605;70864-060 Brasília DF - Brasil; E-mail:pratesir@unb.br

Conflict of interest: There is no conflict of interest to declare.

Received 27 June 2011; Received in final form 09 August 2011; Accepted 16 August 2011
} 
establishes the importance of genetic factors in the development of ASDs².

ASDs were considered to be rare until a few decades ago, but their prevalence has increased more than tenfold over the past 20 years. Their estimated prevalence is $0.9 \%$ in the United States ${ }^{3}$, although data from a recent review of 47 studies conducted in 17 different countries since 1966 found that the prevalence ranged from 0.6 to $0.7 \%$, or one child in about 150 children $^{4}$. In spite of the controversy regarding whether this is a real rise in the number of cases or the result of increased publicity and better diagnostic criteria, it remains clear that ASDs are disorders that produce major challenges for the families and society. No reliable studies focusing on the prevalence of ASDs have been conducted in Brazil.

Although celiac disease (CD) is classically defined as an immune-mediated chronic small-intestinal enteropathy, which is triggered by the ingestion of gluten from wheat, barley and rye in genetically predisposed individuals, CD could be more appropriately described as a multisystem disorder, often showing extra-intestinal symptoms and potentially affecting any organ or body system, including the nervous system $^{5}$. The diagnosis of CD is traditionally based on positive serological tests and on a biopsy of the upper small intestine revealing varying degrees of villous atrophy, crypt hyperplasia, and intraepithelial lymphocytes. The serological tests commonly used are the IgA-endomysial antibody (IgA-EMA), which possesses specificity approaching $100 \%$, and the IgAanti-transglutaminase antibody (IgA-tTG), which does not have the same specificity but, since it is an enzyme-linked immunosorbent immunoassay (ELISA), it is less expensive and less observer-dependent ${ }^{6}$.

The association between $\mathrm{CD}$ and central nervous system dysfunction was initially suggested several decades ago by Cooke and Thomas-Smith ${ }^{7}$, and their initial review was followed by numerous articles and case reports on patients with established $\mathrm{CD}$ and different neurological manifestations, including neuropathy, ataxia, migraines and epilepsy ${ }^{8,9}$.

Some authors have raised the hypothesis that gluten sensitivity may exist in patients with normal jejunal mucosa and negative anti-transglutaminase (IgA-tTG) and IgA-EMA tests. IgA-EMA and IgA-tTG detections are specific for the presence of enteropathy and are excellent indicators of $\mathrm{CD}$. However, these markers are often not detectable in patients with neurological manifestations, particularly in the absence of enteropathy. Although there is not always a diagnostic for gluten sensitivity, the presence of positive antigliadin antibody (IgA-AGA) tests in these patients would raise a high degree of suspicion and could be considered as an indicator for further testing and follow-up ${ }^{10}$.

Screening studies performed over the last decade in Brazil have shown uneven prevalence rates for $\mathrm{CD}$ in different regions of Brazil, ranging from 1:52 to 1:417 in the general population $^{11,12}$ and from 1:214 to 1:681 in presumably healthy blood donors ${ }^{13,14}$. Among children younger than 15 years-old, originating from the same geographical region and pertaining to a similar socioeconomic stratum in which the present study was performed, a prevalence of 1:185 (0.54\%) was found ${ }^{12}$. Consequently, it seems that CD prevalence in Brazil is similar to what was found in European countries and in the USA, where an overall prevalence ranging from 1:150 to 1:250 is generally accepted ${ }^{15}$.

Increased presence of gastrointestinal disorders in ASD patients is a recurring theme, both in the medical literature and among the parents and caregivers of autistic children. Several studies have reported that gluten-free and caseinfree diets ameliorated autistic symptoms, although sound evidence that this association really exists and complete agreement among authors regarding this topic is still lacking ${ }^{16-19}$. Similarly, over the past decade, several authors have suggested that links may exist between $\mathrm{CD}$ and $\mathrm{ASDs}{ }^{20}$ and between $\mathrm{CD}$ or gluten sensitivity and psychiatric disorders ${ }^{21,22}$, but these indications have been contradicted by other reports ${ }^{23}$.

The aims of the present study were to evaluate the existence of a possible relationship between $\mathrm{CD}$ or gluten sensitivity and ASD, to determine occurrences of CD and/or increased levels of IgA-AGA among a group of children and adolescents affected by ASD and, conversely, to assess occurrences of ASD among a group of biopsy-proven celiac patients.

\section{METHODS}

The relationship between ASD and CD or ASD and gluten sensitivity was assessed by evaluating a group of $147 \mathrm{pa}-$ tients with ASD for simultaneous occurrences of CD and/or increased levels of IgA-AGA. Conversely, occurrences of ASD were assessed in a group of 211 celiac patients followed-up at the Walk-in CD Clinic of the Hospital from the University of Brasília, Brasília, Federal District, in Brazil. The Hospital from the University of Brasília is a general hospital attending mainly the low-income population originating from the outskirts and suburban regions of the city of Brasília. Racially, this is a predominantly mixed-blood population in which a considerable contribution of European ancestry can be detected in association with variable proportions of other races, mainly Black African and, to a lesser extent, Amerindian.

This study received approval from the Ethics Committee of the School of Health Sciences from the University of Brasília, and informed consent for participation in the study and for publication of the results was obtained from all the eligible adult patients or, in the case of children or adolescents, from their parents or guardians.

Among the 211 biopsy-proven celiac patients who were included in this study, there were 66 males and 145 females (age range: 1 to 48 years-old; mean age: 15.7 years-old). These 
patients had been diagnosed as presenting CD, in accordance with the revised criteria of the European Society of Pediatric Gastroenterology and Nutrition (ESPGAN) ${ }^{24}$. All the celiac patients were evaluated, and members of their families agreed to answer questions, as indicated in the DSM-IV, concerning the possible existence of behavioral abnormalities suggestive of ASD.

A small proportion of the patients with ASD was identified through two local societies of parents of autistic children. A larger proportion was found among students in special education classes organized by the Federal District Department of Education. The socioeconomic strata and racial characteristics of the ASD patients were comparable with those of the study group of celiac patients. Among the 147 ASD patients who were enrolled in the study, there were 127 males and 20 females (age range: 1 to 35 years-old; mean age, 8 years-old). All the patients were diagnosed by accredited medical professionals and fulfilled the diagnostic criteria of the DSM-IV for ASD. None of the patients was on a gluten-free diet (GFD).

Blood samples were centrifuged, and the resulting sera were stored at $-20^{\circ} \mathrm{C}$ until their use. To exclude individuals with a possible IgA deficiency, IgA levels were measured by turbidimetric immunoquantification (COBAS MIRA, Roche Diagnostic Systems). IgA and IgG antigliadin antibodies (IgAAGA and IgG-AGA) and IgA anti-transglutaminase antibodies (IgA-tTG) were assessed by means of the standard ELISA (Quanta Lite ${ }^{\mathrm{TM}}$ IgA and IgG gliadin and human IgA-tTG, INOVA Diagnostic, Inc. CA, USA). According to the manufacturer's instructions, the upper limit of the normal range was established as 20 arbitrary units. All patients who displayed values above the upper limit in the antigliadin or anti-transglutaminase tests underwent further testing for the presence of anti-endomysium-specific antibodies (IgA-EMA). The IgA-EMA assay was performed using indirect immunofluorescence with cryosections of distal monkey esophagus (Binding Site, Birmingham, UK). Two independent observers examined all the slides, and the presence of brilliant green reticulin-like staining of smooth muscle under the fluorescence microscope was considered a positive result. In the present study, the IgA-tTG test (more sensitive but less specific) was used as a preliminary screening test, while the IgA-EMA one was considered a confirmatory test.

\section{Statistical analysis}

The prevalence of CD and ASD and the increased level of IgA-AGA were estimated together with their exact binomial $95 \%$ confidence intervals $(95 \% \mathrm{CI})$. To compare the prevalence between groups, the exact p-value for the $\chi^{2}$ statistic was calculated (based on binomial distribution).

\section{RESULTS}

Among the 147 ASD patients, five displayed abnormal results in the IgA-AGA test, and one showed a weakly positive result in the IgA-tTG test. These six patients were subsequently tested for the presence of IgA-EMA with negative results. The test results and clinical data on these patients can be seen in Table 1.

Among the 211 biopsy-proven CD patients followed at the Walk-in CD Clinic of the Hospital from University of Brasília, two cases of ASDs were identified: an 11-year-old boy who fulfilled all of the DSM-IV criteria for an autistic disorder and a seven -year-old boy with Asperger's syndrome. Both patients had been referred by their attending physicians due to the presence of gastrointestinal symptoms, mainly composed of frequent abdominal cramps and diarrheic episodes. A GFD was strictly followed only by one of the two patients, who showed progressive improvement in gastrointestinal symptoms, although no behavioral improvement could be detected.

Since no data on the prevalence of ASDs in Brazil are available as a reference for the prevalence of ASDs in the general population, we used the prevalence found by the latest surveillance summaries of Center of Disease Control (CDC) autism and development disabilities monitoring network, United States, which was conducted in a population of 307,790 eight-year-old children ${ }^{3}$. The prevalence of ASDs in patients with $\mathrm{CD}$ was $0.95 \%(95 \% \mathrm{CI}=0.11-3.82)$ and it was not statistically different from the prevalence of $0.9 \%$ found in the general US population ( $\mathrm{p}=1.00)$, as seen in Table 2.

No cases of CD were found among the 147 patients with ASD. The reference group, regarding the prevalence of CD in our area, was composed of 2,034 children younger than 15 years-old (age range: 1 to 14 years-old; mean age: 8 years-old),

Table 1. Clinical and laboratory data on the six ASD patients with abnormal results from serological tests.

\begin{tabular}{lcccccll} 
Patients & Sex & Age $(\mathrm{y})$ & IgG-AGA & IgA-AGA & IgA-tTG & IgA-EMA & Symptoms \\
\hline 1 & M & 14 & 45.1 & 9.9 & 10.9 & Negative & No gastrointestinal symptoms \\
2 & M & 15 & 3.0 & 38.8 & 8.9 & Negative & No gastrointestinal symptoms \\
3 & M & 6 & 3.4 & 15.3 & 29.3 & Negative & Constipation and occasional diarrhea \\
4 & M & 4 & 12.7 & 50.6 & 12.6 & Negative & No gastrointestinal symptoms \\
5 & M & 5 & 5.1 & 44.1 & 6.3 & Negative & Anemia, constipation, bloating, abdominal \\
& & & & & & cramps, mouth ulcers, and chronic fatigue \\
6 & F & 12 & 6.8 & 45.4 & 8.8 & Negative & Constipation and occasional abdominal cramps \\
\hline
\end{tabular}

ASD: autism spectrum disorder; M: masculine; F: feminine. 
Table 2. Prevalence of ASDs found among our 211 biopsy-proven celiac disease patients, and estimated prevalence of ASDs found in a population of 307,790 eight-year-old children in the USA ${ }^{3}$.

\begin{tabular}{lccc} 
Groups & $\mathrm{n}$ & $\begin{array}{c}\text { Prevalence } \\
\text { of ASDs }\end{array}$ & $\begin{array}{c}\text { 95\% }^{*} \mathrm{Cl}^{*} \\
\text { (between groups) }^{\dagger}\end{array}$ \\
\hline Prevalence of ASDs among our celiac patients & 211 & 0.95 & $(0.11-3.82)$ \\
Prevalence of ASDs in the USA population (307,790) & & 0.90 & 1.00 \\
\hline
\end{tabular}

*Based on binomial distribution; ${ }^{+}$Exact test; Post-hoc power analysis=1.000; ASD: autism spectrum disorder.

Table 3. Prevalence of CD among our 147 ASD patients and in a group of 2,034 children and adolescents originating from the same geographical region and from a similar low-income stratum.

\begin{tabular}{lccc} 
Groups & $\mathrm{n}$ & CD prevalence & $\begin{array}{c}\text { 95\%Cl* }^{*} \\
\text { (between groups) }^{\dagger}\end{array}$ \\
\hline Prevalence of CD among ASD patients & 147 & 0.00 & $(0.00-2.48)$ \\
Prevalence of CD among subjects without ASDs & 2034 & 0.54 & 0.63 \\
\hline
\end{tabular}

*Based on binomial distribution; ${ }^{+}$Exact test; Post-hoc power analysis=0.999993; ASD: autism spectrum disorder; CD: celiac disease.

Table 4. Prevalence of IgA-AGA in ASD patients and in 132 non-celiac children originating from the same geographical region and from a similar low-income stratum.

\begin{tabular}{|c|c|c|c|c|}
\hline Groups & $\mathrm{n}$ & $\begin{array}{l}\text { IgA-AGA } \\
\text { Prevalence }\end{array}$ & $95 \% \mathrm{Cl}^{*}$ & $\begin{array}{c}p \text {-value } \\
\text { (between groups) }^{\dagger}\end{array}$ \\
\hline Prevalence of IgA-AGA in patients with ASDs & 147 & 3.4 & $(1.11-7.76)$ & 0.08 \\
\hline Prevalence of IgA-AGA in non-celiac patients without ASDs & 131 & 9.3 & & \\
\hline
\end{tabular}

*Based on binomial distribution; ${ }^{~}$ Exact test; Post-hoc power analysis=0.978618; ASD: autism spectrum disease.

who were part of a previous CD prevalence screening study that we conducted, originating from the same geographical region and pertaining to a low-income population similar to the celiac group of this study. The prevalence of $\mathrm{CD}$ in this group was $0.54 \%$ and no cases of ASD were found among such children. Consequently, the prevalence of $\mathrm{CD}$ in patients with ASD was $0.00 \%$ ( $95 \% \mathrm{CI}=0.00-2.48)$ and it was not statistically different from the prevalence found in children in the same region (Table 3).

To evaluate the possible existence of gluten sensitivity in ASD patients, we used a reference group consisting of 132 children who displayed varying degrees of gastrointestinal symptoms (age range: 1 to 12 years-old; mean age: 5.8 years-old), and who were part of an ongoing study on the prevalence of IgA-AGA in non-celiac (IgA-EMA and IgA-tTG negative) children. The prevalence of IgA-AGA among these children, originating from the same geographical region and socioeconomic stratum, was $9.3 \%$, while the prevalence of IgA-AGA in patients with ASD was 3.4\% (95\% CI=1.11-7.76), with $\mathrm{p}=0.08$ (Table 4).

\section{DISCUSSION}

As previously stated, the wide phenotypic heterogeneity suggests that ASDs may possibly encompass several different specific disorders with different etiologies sharing a common behavioral clinical picture. The presently available data point towards probable involvement of multiple interacting genes and environmental modifiers in the pathogenesis of autism $^{25}$.

The suggestion that CD might be involved in the pathogenesis of autism has mostly been based on the leaky-gut hypothesis, i.e., abnormal intestinal mucosa would permit excessive absorption of short-chain peptides produced from incomplete digestion of dietary gluten in the lumen of the small intestine, through defective action of peptidases. These short peptides, structurally similar to endorphin, could provoke an immune reaction or act as exorphins, thereby directly affecting the nervous system. However, a recent consensus report concluded that the evidence for abnormal gastrointestinal permeability in individuals with ASDs is presently limited and additional properly powered prospective studies with appropriate controls are needed in order to determine the role of abnormal permeability in neuropsychiatric manifestations of ASDs ${ }^{16}$. Several authors have reported that children with ASDs may experience more constipation, loose stools, recurrent abdominal pain, bloating, and excessive flatulence than presented by non-affected children ${ }^{18,26}$.

Although gastrointestinal problems in individuals with ASDs may go undiagnosed because of atypical symptoms and/or difficulties in communicating with nonverbal patients, it is difficult to establish whether their prevalence is higher than is seen in the general population, due mainly to the lack of prospective well-controlled studies. The presumed association between an excess of gastrointestinal symptoms in children with autism and worsening of their behavior often results in implementation of restrictive diets, mainly targeting 
casein and gluten in the hope of improving their symptoms. Several studies and reviews have addressed the topic of the existence of a possible gut-to-brain connection and the effects of dietary intervention in autism, with varying results ${ }^{17}$. In a recent extensive literature review on this topic, Millward et $a{ }^{27}$ concluded that the current body of evidence to suggest that dietary therapy approaches are effective is still poor, and that large-scale, good-quality randomized controlled trials are needed.

The assumption that gastrointestinal symptoms are excessively frequent in autistic children has raised the hypothesis that greater prevalence of CD could also exist among patients with autism, given that one possible point in common between these two very different diseases would be the increased intestinal permeability, which is present in both disorders. However, the results from the few studies on the possible association between $\mathrm{CD}$ and autism have not shown consistent results ${ }^{20-23}$.

Additionally, as appropriately noted by Lionetti et al. ${ }^{28}$, it is important to remember that autism is a neurological disorder of early brain development and therefore it is difficult to establish a temporal correlation between the presence of abnormalities of the central nervous system and the gluten intake, which usually begins after the first six months of age. In the majority of children with diagnosis of autism, careful analysis on their histories will reveal that the symptoms began before they reached 18 months of age. This early onset only provides a limited period of time for the infant to have begun to consume gluten-containing foods.

Our results showed that the prevalence of CD in patients with autism was not greater than the prevalence found in a group of 2,034 healthy children originating from the same geographical area. We also found that the prevalence of autism was not significantly greater among our group of 211 biopsy-confirmed CD patients. The possibility of higher gluten sensitivity in ASD children, which would be substantiated by increased presence of IgA-AGA, was also ruled out since there was no significant difference in the prevalence of these antibodies in comparison with the prevalence found in a sample of 131 non-celiac children of similar socioeconomic level originating from the same city.
In conclusion, although the profusion of studies reporting clinical and, especially, behavioral improvement with gluten-exclusion diets in patients with autism cannot be simply ignored, it is at present difficult to statistically demonstrate that there is an association between ASD and CD or between ASD and gluten sensitivity. The reported deleterious effects on brain function, the behavior of children with ASD, consequent to gluten intake, and the frequently reported clinical improvement with restriction diets, if present, are possibly due to other and not completely clarified mechanisms. In the case of gluten sensitivity, in the absence of reliable biomarkers, the diagnosis is still dependent on establishing an exclusion diet in patients who experience distress when eating gluten-containing products ${ }^{29}$.

With the present data, we are forced to agree with the previous work by Pavone et al. ${ }^{23}$, who concluded that concomitant occurrences of autism and CD in the same individuals are most likely due to pure coincidence.

Although we feel that performing routine screening for CD in all patients with ASD is neither justified nor cost-effective, one should also consider that $\mathrm{CD}$ is a disease with reliable serological and genetic markers, whereas the ASD diagnosis is based on clinical grounds probably encompassing different disorders with a common clinical expression. It is possible that different results would have been obtained if a specific subset of ASD patients had been selected (e.g., only children with regressive autism).

The main limitation of the present paper is that even though both disorders are lifelong conditions, the age of onset of the CD is variable and some of the ASD patients could still develop this disease in the future. Another limitation is that although the source of all patients with ASDs were regional societies of parents of autistic children and all diagnoses had been made by accredited medical professionals, we were only able to perform a complete evaluation in person on a subset of these patients. It is possible that other clinical entities (e.g. fragile X syndrome) could have been included in the group of ASD patients. Additionally, due to the complete lack of data regarding the prevalence of ASDs in Brazil, we used the prevalence of ASD in the USA based on the latest CDC report ${ }^{3}$, as a reference point for statistical analysis.

\section{References}

1. Johnson CP, Myers SM, and the Council on Children with Disabilities. Identification and evaluation of children with autism spectrum disorders. Pediatrics 2007;120:1183-1215.

2. Bailey A, Le Couteur A, Gottesman I, et al. Autism as a strongly genetic disorder: evidence from a British twin study. Psychol Med 1995; 25:63-77.

3. CDC. Prevalence of autism spectrum disorders - Autism and Developmental Disabilities Monitoring Network, United States, 20006 In: Surveillance Summaries, December 18, 2009. MMWR 2007;58 (No.SS-10):1-24.

\footnotetext{
4. Fombonne E. Epidemiology of pervasive developmental disorders. Pediatr Res 2009;65:591-598.

5. Green PH, Cellier C. Celiac disease. N Engl J Med 2007;357: 1731-1743.

6. Green PH, Jabri B. Celiac disease. Ann Rev Med 2006;57:207-221.

7. Cooke WT, Thomas-Smith WT. Neurological disorders associated with adult coeliac disease. Brain 1966;89:683-722.

8. Morris JS, Ajdukiewicz AB, Read AE. Neurological disorders and adult coeliac disease. Gut 1970;11:549-554.
} 
9. Muller AF, Donnelly MT, Smith CM, Grundman MJ, Holmes GK, Toghill PJ. Neurological complications of celiac disease: a rare but continuing problem. Am J Gastroenterol 1996;91:1430-1435.

10. Hadjivassiliou M, Sanders DS, Grünewald RA, Woodroofe N, Boscolo S, Aeschlimann D. Gluten sensitivity: from gut to brain. Lancet Neurol 2010;9:318-330

11. Trevisol C, Brandt KG, Silva GA, Crovella S, Ventura. A high prevalence of unrecognized celiac disease in an unselected hospital population in North-Eastern Brazil (Recife-Pernambuco). J Pediatr Gastroenterol Nutr 2004;39:214-215.

12. Pratesi R, Gandolfi L, Garcia SG, et al. Prevalence of coeliac disease: unexplained age-related variation in the same population. Scand $J$ Gastroenterol 2003;38:747-750

13. Oliveira RP, Sdepanian VL, Barreto JA, et al. High prevalence of celiac disease in Brazilian blood donor volunteers based on screening by IgA antitissue transglutaminase. Eur J Gastroenterol Hepatol 2007;19: 43-49.

14. Gandolfi L, Pratesi R, Cordoba JC, Tauil PL, Gasparin M, Catassi C. Prevalence of celiac disease among blood donors in Brazil. Am J Gastroenterol 2000;95:689-692

15. Dubé C, Rostom A, Sy R, et al. The prevalence of celiac disease in average-risk and at-risk Western European populations: a systematic review. Gastroenterology 2005;128(Suppl 1):S57-S67.

16. Buie T, Campbell DB, Fuchs GJ $3^{\text {rd }}$, et al. Evaluation, diagnosis, and treatment of gastrointestinal disorders in individuals with ASDs: a consensus report. Pediatrics 2010;125(Suppl 1):S1-S18.

17. Erickson CA, Stigler KA, Corkins MR, Posey DJ, Fitzgerald JF, McDougle CJ. Gastrointestinal factors in autistic disorder: a critical review. J Autism Dev Disorders 2005;35:713-727.

18. Molloy CA, Manning-Courtney P.Prevalence of chronic gastrointestinal symptoms in children with autism and autistic spectrum disorders. Autism 2003;7:165-171.
19. Ibrahim SH, Voigt RG, Katusic SK, Weaver AL, Barbaresi WJ. Incidence of gastrointestinal symptoms in children with autism: A populationbased study. Pediatrics 2009;124:680-686.

20. Barcia G, Posar A, Santucci M, Parmeggiani A. Autism and coeliac disease. J Autism Dev Disord 2008;38:407-408.

21. Kalaydjian AE, Eaton W, Cascella N, Fasano A. The gluten connection: the association between schizophrenia and celiac disease. Acta Psychiatr Scand 2006;113:82-90.

22. Cascella NG, Kryszak D, Bhatti B, et al. Prevalence of celiac disease and gluten sensitivity in the United States. Clinical antipsychotic trials of intervention effectiveness study population. Schizophr Bull 2011:37:94-100.

23. Pavone L, Fiumara A, Bottaro G, Mazzone D, Coleman M. Autism and celiac disease: failure to validade the hypothesis that a link might exist. Biol Psychiatry 1997;42:72-75.

24. Walker-Smith JA, Guandalini S, Schmitz J, Shmerling DH, Visakorp JK. Revised criteria for diagnosis of coeliac disease. Arch Dis Child 1990;65:909-911.

25. Muhle R, Trentacoste SV, Rapin I. The genetics of autism. Pediatrics 2004;113:472-486.

26. Kuddo T, Nelson KB. How common are gastrointestinal disorders in children with autism? Curr Opin Pediatr 2003;15:339-343.

27. Millward C, Ferriter M, Calver S, Connell-Jones G. Gluten- and caseinfree diets for autistic spectrum disorder. Cochrane Database Syst Rev 2008;16:CD003498.

28. Lionetti E, Francavilla R, Pavone P, et al. The neurology of coeliac disease in childhood: what is the evidence? A systematic review and meta-analysis. Dev Med Child Neurl 2010;52:700-707.

29. Sapone A, Lammers KM, Casolaro V, et al. Divergence of gut permeability and mucosal immune gene expression in two glutenassociated conditions: celiac disease and gluten sensitivity. BMC Med 2011;9:23. 